\title{
Changes in cell shape and desmin intermediate filament distribution are associated with down-regulation of desmin expression in C2C12 myoblasts grown in the absence of extracellular $\mathrm{Ca}^{2+}$
}

C.S. Mermelstein,

L.M. Amaral, M.I.L. Rebello, J.S.N. Reis, R. Borojevic and M.L. Costa
Departamento de Histologia e Embriologia, Instituto de Ciências Biomédicas, Universidade Federal do Rio de Janeiro, Rio de Janeiro, RJ, Brasil
Correspondence

C.S. Mermelstein

Departamento de Histologia e

Embriologia, ICB, UFRJ

21941-590 Rio de Janeiro, RJ

Brasil

Fax: +55-21-2237-0844

E-mail: mermelstein@ufrj.br

Research supported by CNPq, FAPERJ, FUJB-UFRJ, and PRONEXBrasil.

Presented at the XI Congresso Brasileiro de Biologia Celular, Campinas, SP, Brazil, July 15-18, 2004.

Received July 7, 2004 Accepted March 2, 2005 $\ldots \ldots \ldots \ldots \ldots \ldots \ldots$

\begin{abstract}
Desmin is the main intermediate filament (IF) protein of muscle cells. In skeletal muscle, desmin IFs form a scaffold that interconnects the entire contractile apparatus with the subsarcolemmal cytoskeleton and cytoplasmic organelles. The interaction between desmin and the sarcolemma is mediated by a number of membrane proteins, many of which are $\mathrm{Ca}^{2+}$-sensitive. In the present study, we analyzed the effects of the $\mathrm{Ca}^{2+}$ chelator EGTA $(1.75 \mathrm{mM})$ on the expression and distribution of desmin in $\mathrm{C} 2 \mathrm{C} 12$ myoblasts grown in culture. We used indirect immunofluorescence microscopy and reverse transcription polymerase chain reaction (RT-PCR) to analyze desmin distribution and expression in $\mathrm{C} 2 \mathrm{C} 12$ cells grown in the presence or absence of EGTA. Control C2C12 myoblasts showed a well-spread morphology after a few hours in culture and became bipolar when grown for $24 \mathrm{~h}$ in the presence of EGTA. Control $\mathrm{C} 2 \mathrm{C} 12$ cells showed a dense network of desmin from the perinuclear region to the cell periphery, whereas EGTA-treated cells showed desmin aggregates in the cytoplasm. RT-PCR analysis revealed a down-regulation of desmin expression in EGTA-treated $\mathrm{C} 2 \mathrm{C} 12$ cells compared to untreated cells. The present results suggest that extracellular $\mathrm{Ca}^{2+}$ availability plays a role in the regulation of desmin expression and in the spatial distribution of desmin IFs in myoblasts, and is involved in the generation and maintenance of myoblast cell shape.
\end{abstract}

\section{Introduction}

$\operatorname{Desmin}(53 \mathrm{kDa})$ is the main intermediate filament protein of striated muscle cells. This extensive network of $10-\mathrm{nm}$ intermediate abundant protein polymerizes to form an
Key words - Extracellular $\mathrm{Ca}^{2+}$

- EGTA

- Myoblasts

- Desmin

- Intermediate filaments

- RT-PCR filaments that span the nuclear envelope to the sarcolemma and link myofibrils together in a three-dimensional scaffold around $\mathrm{Z}$ discs, forming an extrasarcomeric component of the muscle cytoskeleton (1). Therefore, desmin has structural domains that 
direct or indirectly link this protein to the nuclear membrane, Z-disk components and the sarcolemma. It has been shown that desmin is present in subsarcolemmal costameres in association with membrane and membrane-associated proteins such as the dystrophin protein complex (2), spectrin, ankyrin, integrins, vinculin, and $\alpha$-actinin (3). Mutational analysis indicates that it is the head domain of desmin that is specialized for its association with the sarcolemma (4). The association of desmin with the sarcolemma is supposed to be dependent on the versatile cytoskeletal linker protein plectin (5), which is a very large size polypeptide $(>500 \mathrm{kDa})$ abundant in the subsarcolemmal region. Many transmembrane components of these complexes are $\mathrm{Ca}^{2+}$-sensitive in their intra- and extracellular domains. Variations in extracellular $\mathrm{Ca}^{2+}$ concentration are one of the regulatory mechanisms involved in the activation of these membrane complexes through conformational changes $(6,7)$. One of the evolutionary advantages of $\mathrm{Ca}^{2+}$ ions as regulators of protein structure and function is the possibility of rapid changes in their concentration (8).

To investigate the function of desmin in all muscle types in vivo, desmin null mice were generated by homologous recombination (9). Although a considerable number of these mice are viable and fertile, they present a multisystem disorder involving cardiac, skeletal and smooth muscle that begins early during postnatal life. Histological and electron microscopic analysis of both heart and skeletal muscle tissues reveals severe disruption of muscle architecture and degeneration, including perturbation of myofibril anchorage to the sarcolemma. The study of desmin is especially relevant because a number of desmin-related pathologies have been described (10). Desmin-myopathies consist of alterations in the distribution of desmin, particularly the presence of desmin aggregates and inclusions in the cytoplasm of myogenic cells (11).
Previous work from our group suggested a role for extracellular $\mathrm{Ca}^{2+}$ in the regulation of the spatial distribution of microfilaments, microtubules, intermediate filaments, and adhesion sites in myoblasts (12). The present investigation was undertaken to study the effects of extracellular $\mathrm{Ca}^{2+}$ withdrawal on cell shape and on the expression and distribution of desmin in myoblasts grown in culture.

\section{Material and Methods}

\section{Antibodies and fluorescent probes}

Rabbit polyclonal anti-desmin antibody was purchased from Sigma (St. Louis, MO, USA) and fluorescein isothiocyanate-goat anti-rabbit IgG antibody was purchased from Jackson Immunoresearch Laboratories (West Grove, PA, USA). The nuclear dye DAPI (4'6-diamino-2-phenylindole dihydrochloride) was purchased from Molecular Probes Inc. (Eugene, OR, USA).

\section{Cell cultures}

The mouse skeletal muscle cell line $\mathrm{C} 2 \mathrm{C} 12$ was obtained from the Rio de Janeiro Cell Bank (PABCAM, Federal University of Rio de Janeiro, Rio de Janeiro, RJ, Brazil). Cells were routinely grown in Dulbecco's modified Eagle's medium containing 20\% fetal calf serum, $1 \% \mathrm{~L}$-glutamine and $1 \%$ penicillin-streptomycin (all from Sigma), in a humidified $5 \% \mathrm{CO}_{2}$ atmosphere at $37^{\circ} \mathrm{C}$. Cells were grown at a low density of $5 \times 10^{5}$ cells/ 35-mm culture dishs (Nunc, Roskilde, Denmark) onto aclar plastic coverslips (ProPlastics Inc., Linden, NJ, USA) coated with rat collagen. EGTA (Sigma) at a concentration of $1.75 \mathrm{mM}(12,13)$ was added to the medium of subconfluent cultures. Both control and EGTA-treated cultures were fed daily with fresh medium containing or not EGTA. After $24 \mathrm{~h}$ of EGTA exposure, live cultures were observed by phase contrast microscopy, or cells were submitted to fluo- 
rescence microscopy or to semi-quantitative polymerase chain reaction (RT-PCR).

\section{Immunofluorescence and phase contrast microscopy}

For immunofluorescence microscopy, cultures were rinsed with phosphate-buffered saline (PBS) and fixed with 2\% formaldehyde in PBS for $3 \mathrm{~min}$ at room temperature (14). They were then permeabilized with $0.5 \%$ Triton-X 100 (Sigma) in PBS three times for $10 \mathrm{~min}$. The same solution was used for all subsequent washing steps. Cells were incubated with anti-desmin polyclonal antibody at $1: 100$ dilution for $1 \mathrm{~h}$ at $37^{\circ} \mathrm{C}$ in a humid chamber. After incubation, cells were washed for $30 \mathrm{~min}$ and incubated with secondary antibody for $1 \mathrm{~h}$ at $37^{\circ} \mathrm{C}$ in a humid chamber, and then washed for $30 \mathrm{~min}$. After a 30-min wash with PBS, the nuclear dye DAPI was added at $0.1 \mu \mathrm{g} / \mathrm{ml}$ in $0.9 \% \mathrm{NaCl}$ for $5 \mathrm{~min}$. Cells were washed for $5 \mathrm{~min}$ with $0.9 \% \mathrm{NaCl}$ and specimens were mounted in glycerol containing, by weight, $5 \%$ n-propyl gallate, $0.25 \%$ 1,4-diazabicyclo[2.2.2] octane and $0.0025 \%$ para-phenylenediamine (all from Sigma). Cells were examined with an Axiovert 100 epifluorescence inverted light microscope (Carl Zeiss, Oberkochen, Germany) using filter sets that were selective for fluorescein or blue wavelength channel. Images were acquired with a C2400i integrated CCD camera (Hamamatsu Photonics, Shizuoka, Japan) using an Argus 20 image processor (Hamamatsu Photonics). Digitalized images were transferred to a Dell OptiPlex GL 575 computer (Dell Corporate, Round Rock, TX, USA) and plates were mounted using Adobe Photoshop software (Adobe Systems Incorporated, San Jose, CA, USA).

Control experiments with no primary antibody showed only a faint background staining (data not shown).

Live $\mathrm{C} 2 \mathrm{C} 12$ cells grown on collagencoated aclar coverslips were examined and images were acquired by phase contrast microscopy using the same microscope and digital system described above.

\section{Digital image processing and analysis}

Phase contrast images were analyzed using the public domain NIH Image program (developed at the US National Institutes of Health and available on the Internet at http:// rsb.info.nih.gov/nih-image). Pixels with a gray-level over 125 were set to black, and cells were initially isolated with 4 series of erosions and dilations. Cells were then manually separated from their neighbors for proper identification as objects. The parameters area, perimeter, major axis, minor axis, angle, and axis ratio (ratio between the major and the minor axis of cells) were measured. Only cells over 200 pixels in area were considered in order to avoid computing parts of cells. Images were calibrated at 1.02 pixels $/ \mu \mathrm{m}$ using a slide with a grating. After automatically measuring all the cells/objects, data were exported to Excel (Microsoft Corporation, Redmond, WA, USA) and to Statistic for Windows (StatSoft Inc., Tulsa, OK, USA) for statistical analysis.

\section{RNA extraction, reverse transcription, amplification and RT-PCR}

Total cellular RNA from control and 24h EGTA-treated $\mathrm{C} 2 \mathrm{C} 12$ cells was isolated using TRIzol ${ }^{\circledR}$ reagent. The RNA and the cDNA were quantified by spectrophotometry (Spectronic, Genesys 2PC, Rochester, NY, USA). cDNA was synthesized from 3 $\mu \mathrm{g}$ total RNA. RNA was primed with $0.5 \mu \mathrm{g}$ oligo-(dT) $)_{12-18}$ primer (reaction volume: 20 $\mu 1)$. After RNA was denatured (10 min at $70^{\circ} \mathrm{C}$ ) and cooled on ice, the following reagents were mixed and then added: $10 \mathrm{mM}$ of each deoxynucleoside triphosphate (dNTP), $6 \mu 15 \mathrm{x}$ reverse transcription (RT) buffer, $0.1 \mathrm{mM}$ DTT, and $200 \mathrm{U}$ superscript RT (reaction volume: $30 \mu \mathrm{l}$ ). The reaction was performed by incubation for $1 \mathrm{~h}$ at $42^{\circ} \mathrm{C}$. 
Amplification reactions consisted of a 0.2 $\mu \mathrm{M}$ primer for desmin (5' primer sequence: TCTCCCGTGTTCCCT/3' primer sequence: ATACGAGCTAGAGTGGCA; size of PCR product: 571 base pairs), $10 \mathrm{mM}$ of each dNTP, PCR buffer, $5 \mu 1$ of the cDNA reaction, and $0.5 \mathrm{U}$ Taq DNA polymerase. The primer sequence for glyceraldehyde-3-phosphate dehydrogenase (GAPDH) was ATCA CCATCTTCCAGGAGCG (sense) and CCTG CTTCACCACCTTCTTG(antisense). cDNAs from control and EGTA-treated cells were subjected to PCR amplifications with serial dilutions at $0.1,0.01$, and $0.001 \mu \mathrm{g}$. GAPDH expression was used to standardize cDNA under non-saturating conditions at 28 cycles. Amplification was carried out during 33 PCR cycles for desmin, each cycle consisting of a denaturation step at $94^{\circ} \mathrm{C}$ for $1 \mathrm{~min}$, another denaturing step at $94^{\circ} \mathrm{C}$ for $30 \mathrm{~s}$, an annealing step at $60^{\circ} \mathrm{C}$ for $30 \mathrm{~s}$, and an extension step

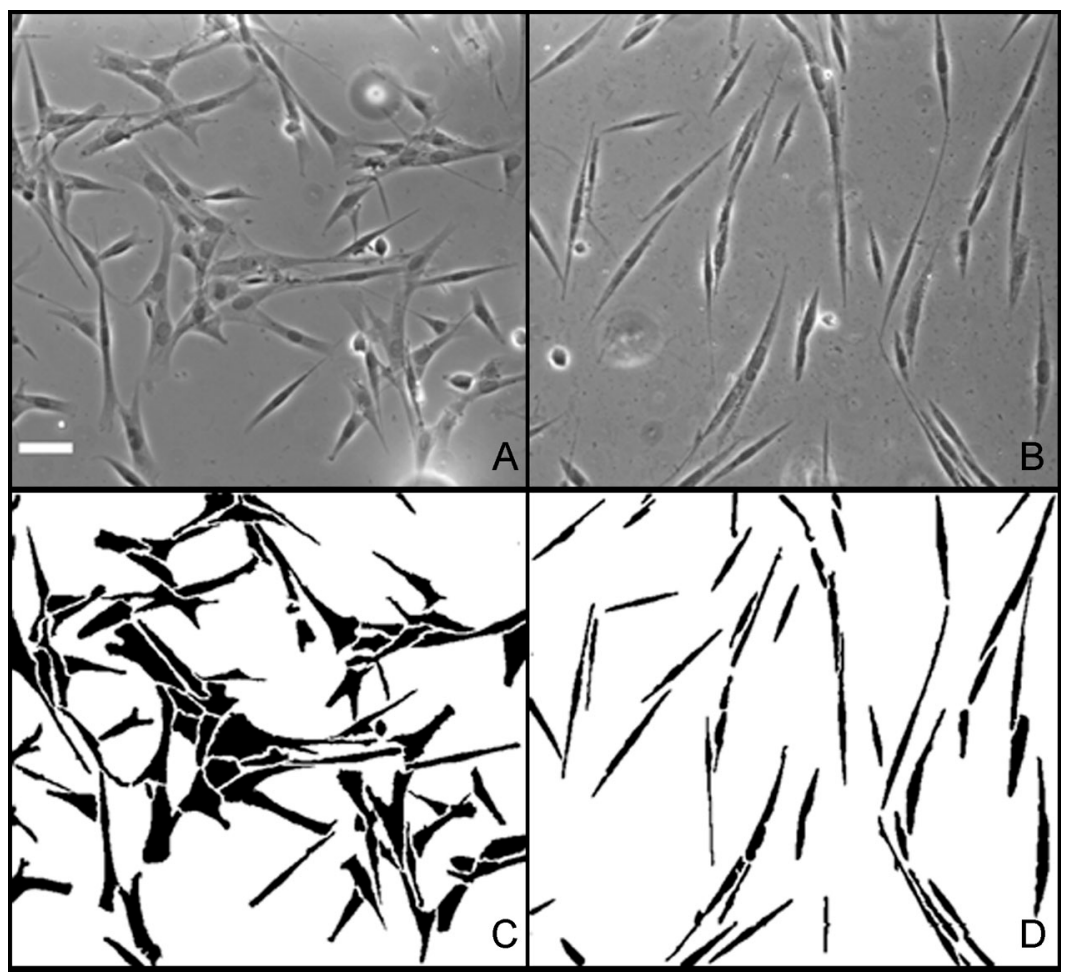

Figure 1. Phase contrast microscopy of $\mathrm{C} 2 \mathrm{C} 12$ grown in the absence of EGTA (control cells, A) or in the presence of $1.75 \mathrm{mM}$ EGTA for $24 \mathrm{~h}$ (B). Digitally processed images of $\mathrm{C} 2 \mathrm{C} 12$ cells in the absence of EGTA (control cells, C) and in the presence of $1.75 \mathrm{mM}$ EGTA (D) (from images A and B, respectively). Bar $=50 \mu \mathrm{m}$. at $72^{\circ} \mathrm{C}$ for $30 \mathrm{~s}$. After the last cycle, incubation for another $5 \mathrm{~min}$ at $72^{\circ} \mathrm{C}$ was performed. The PCR products $(10 \mu \mathrm{l})$ were analyzed by electrophoresis in $1 \%$ agarose gels with Tris-borate-EDTA buffer, stained with $1 \mu \mathrm{g} / \mathrm{ml}$ ethidium bromide for $10 \mathrm{~min}$ and analyzed with the thermal imaging system FTI-500 (Pharmacia, Uppsala, Sweden). Gels were scanned with a Silver Scanner II (LaCie Limited, Hillsboro, OR, USA), at $400 \mathrm{dpi}$, and densitometric profiles were obtained using the public domain NIH Image program (developed at the US National Institutes of Health and available on the Internet at http://rsb.info.nih.gov/nih-image). Areas corresponding to the GAPDH and desmin gel bands from each profile were selected and the number of pixels in each peak was measured. For normalization, desmin expression (number of pixels in the gel band) was divided by GAPDH expression (for 0.1 and $0.01 \mu \mathrm{g}$ cDNA dilution) for both control and EGTA-treated samples, and then plotted on a column chart. Data related to $0.001 \mu \mathrm{g}$ cDNA were not submitted to normalization and analysis since they were considered to be below the minimum level of expression and visualization in the gels.

\section{Results}

To better understand the role of extracellular $\mathrm{Ca}^{2+}$ in the expression and distribution of the muscle-specific protein desmin, skeletal muscle $\mathrm{C} 2 \mathrm{C} 12$ cells were grown in the presence or in the absence of the $\mathrm{Ca}^{2+}$ chelator EGTA $(1.75 \mathrm{mM})$ and then observed by phase contrast microscopy. $\mathrm{C} 2 \mathrm{C} 12$ cells grown in normal medium without EGTA (control cells) were well spread (Figure 1A), whereas the majority of $\mathrm{C} 2 \mathrm{C} 12$ cells grown in medium with EGTA for $24 \mathrm{~h}$ drastically changed to a bipolar morphology (Figure 1B).

Since there were major observable changes in the overall shape of cells treated with EGTA for $24 \mathrm{~h}$, we decided to quantify 
these changes using digital processing of phase contrast microscopy images. Figures $1 \mathrm{C}$ and $1 \mathrm{D}$ show the digitally processed images from control $\mathrm{C} 2 \mathrm{C} 12$ cells and EGTAtreated $\mathrm{C} 2 \mathrm{C} 12$ cells. The parameters area, perimeter, major axis, minor axis, angle, and axis ratio (ratio between the major and the minor axis of cells) were computed for the isolated objects from both processed images. The major significant $(\mathrm{P}<0.001)$ differences between control and EGTAtreated cells concerned the area, minor axis and axis ratio. Area measurements were $29.79 \pm 19.78 \mu \mathrm{m}^{2}$ for control cells and $18.30 \pm 9.70 \mu \mathrm{m}^{2}$ for EGTA-treated cells. Minor axis measurements were $3.04 \pm 1.41$ $\mu \mathrm{m}$ for control cells and $1.39 \pm 0.36 \mu \mathrm{m}$ for EGTA-treated cells. Axis ratio measurements were $5.03 \pm 3.47$ for control cells and 12.78 \pm 6.98 for EGTA-treated cells. The other parameters (perimeter, major axis and angle) were not significantly different between control and EGTA-treated cells (data not shown).

It is possible to see that the areas of control $\mathrm{C} 2 \mathrm{C} 12$ cells were larger than those of EGTA-treated cells (Figure 2A). Not only were the EGTA-treated cells smaller, but they also varied less in shape, as shown in the histogram in Figure 2A and by comparing the standard deviation (SD) of the cell areas described above.

The elongation of the cells can be quantified by the axis ratio (the ratio between the major and the minor axis of cells). The axis ratio of EGTA-treated $\mathrm{C} 2 \mathrm{C} 12$ cells was more than two-fold greater than that of control cells (Figure 2B), showing that treated cells were more elongated than control cells.

To investigate whether the observed cell shape changes in EGTA-treated C2C12 were related to the distribution of the cytoskeleton, we analyzed the organization of the intermediate filament desmin in these cells, since it has been postulated that desmin has a major structural role in maintaining the shape of myogenic cells $(1,15)$. Indirect immunofluorescence microscopy using a polyclonal an- tibody against desmin revealed a characteristic desmin filament organization spanning the distance from a highly concentrated area around the nuclear envelope to the plasma membrane (Figure 3A), while EGTA-treated cells showed a less intense desmin staining, which was visible mainly as dots and short filaments (Figure 3C). The nuclear staining with DAPI showed a normal nuclear pattern in both control cells (Figure 3B) and in cells treated with EGTA for $24 \mathrm{~h}$ (Figure 3D), confirming that EGTA-treated cells were viable.

Since in the immunofluorescence images

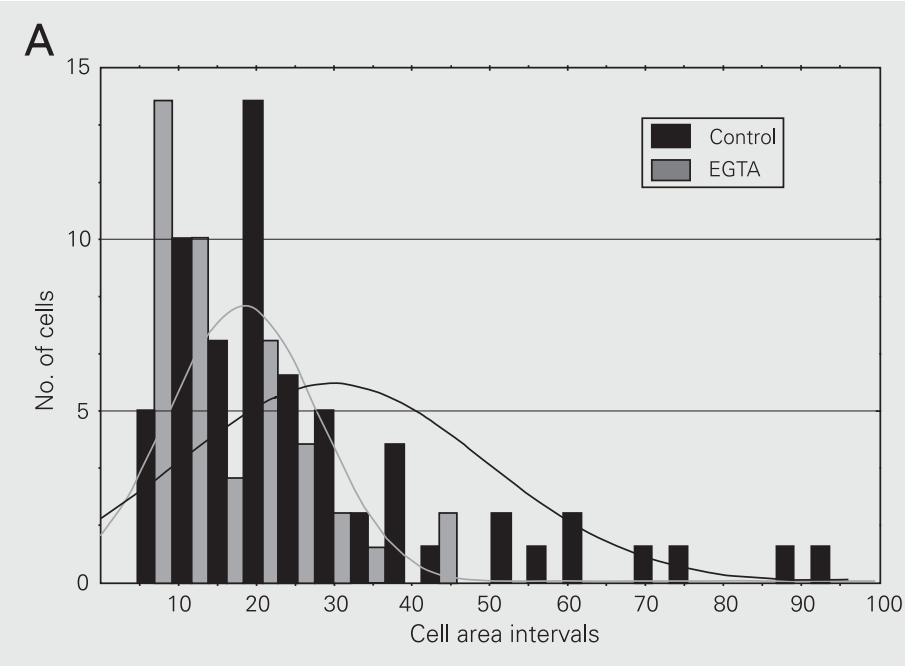

B

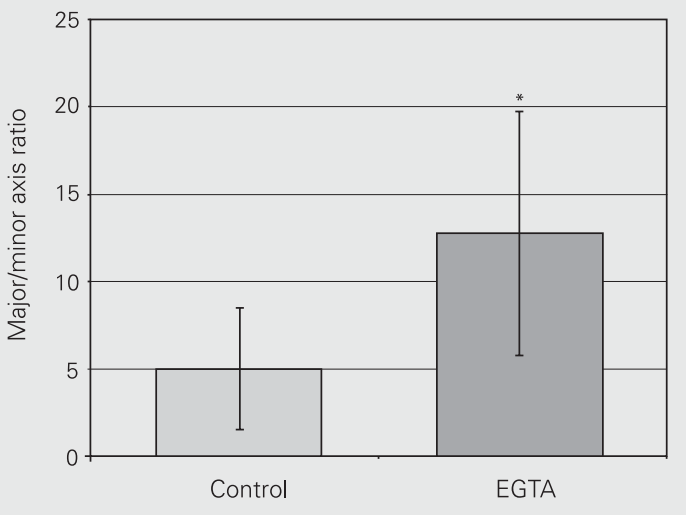

Figure 2. Histogram and best-fit plot of control and EGTA-treated cell area (A), and major/minor axis ratio of control and EGTA-treated cells (B). Axis ratio data from control and EGTA-treated groups were compared statistically $\left({ }^{*} \mathrm{P}<\right.$ $0.0001, t$-test for independent samples). Both histograms were obtained from data described in the Results section. 


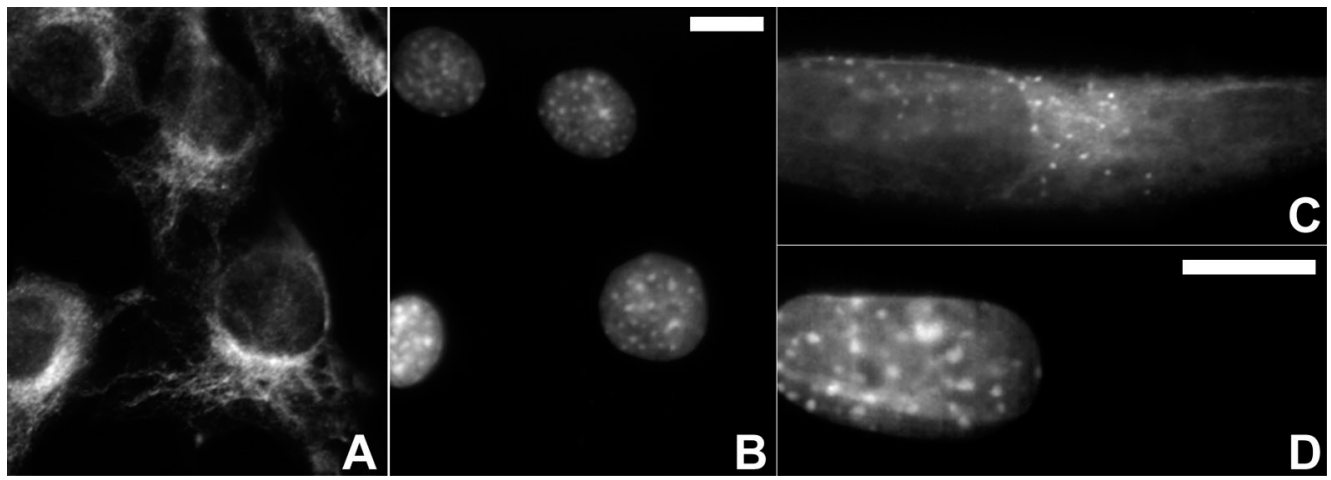

Figure 3. Fluorescence microscopy of $\mathrm{C} 2 \mathrm{C} 12$ cells grown in the absence of EGTA (control cells, $\mathrm{A}$ and $\mathrm{B}$ ) or in the presence of $1.75 \mathrm{mM}$ EGTA for $24 \mathrm{~h}(\mathrm{C}$ and $\mathrm{D})$. Cells were stained with anti-desmin antibody $(\mathrm{A}$ and $\mathrm{C})$ and with the nuclear probe DAPI (B and D). Desmin is present as a dense network of filaments in control cells (A), as opposed to fragmented filaments and dots observed in EGTA-treated cells (C). Bar in $B$ corresponds to $10 \mu \mathrm{m}$ and bar in $D$ corresponds to $5 \mu \mathrm{m}$
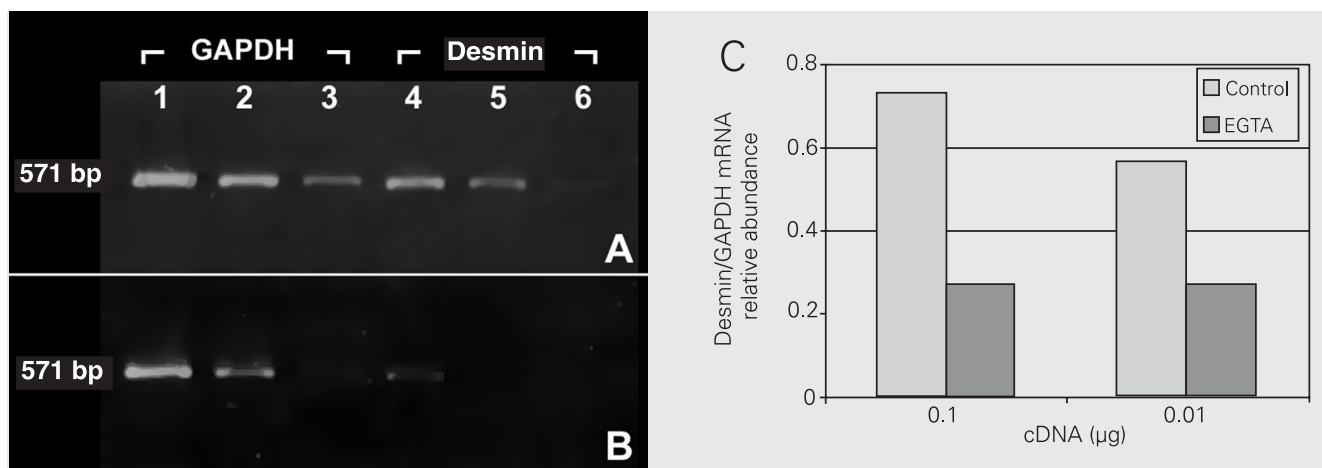

Figure 4. RT-PCR analysis of the expression of desmin in control (A) and in 24-h EGTA-treated C2C12 cells (B). Lanes 1-3 of both agarose gels (A and B) correspond to GAPDH expression $(0.1 \mu \mathrm{g}, 0.01 \mu \mathrm{g}$, and $0.001 \mu \mathrm{g}$ cDNA, respectively). Lanes 4-6 of both agarose gels correspond to desmin expression $(0.1 \mu \mathrm{g}, 0.01 \mu \mathrm{g}$ and $0.001 \mu \mathrm{g} \mathrm{cDNA}$, respectively). C, Comparative expression of desmin in control and EGTA-treated cells after normalization of PCR data (for details, see Material and Methods). GAPDH = glyceraldehyde-3-phosphate dehydrogenase.

of EGTA-treated cells desmin appeared to have a less intense staining, we decided to further analyze desmin expression by RTPCR. In agreement with the immunofluorescence analysis, we confirmed that desmin expression was down-regulated in $\mathrm{C} 2 \mathrm{C} 12$ cells treated with EGTA for $24 \mathrm{~h}$ (Figure 4B) when compared to untreated $\mathrm{C} 2 \mathrm{C} 12$ cells (control) that showed a comparatively higher expression of desmin (Figure 4A). These results can be better visualized in the normalized data obtained by densitometric analysis of the agarose gels shown in Figure 4C.

\section{Discussion}

The present study analyzed the involvement of extracellular $\mathrm{Ca}^{2+}$ in the generation and maintenance of cell shape and its relation with the expression and distribution of the intermediate filament desmin in the mouse skeletal muscle cell line $\mathrm{C} 2 \mathrm{C} 12$.

Well-spread control C2C12 cells (grown without EGTA) changed to a bipolar morphology after $24 \mathrm{~h}$ of EGTA treatment. The quantification of these changes showed substantial modifications in area and in the ratio 
between the major and the minor axis of cells. The cell area of control cells was larger than that of EGTA-treated cells, and the axis ratio of EGTA-treated cells was more than two-fold larger than that of control myoblasts. The lack of differences in perimeter between control and treated cells was due to the elongation of EGTA-treated cells, which is clearly demonstrated by the axis ratio showing that treated cells were thinner and longer than control cells.

$\mathrm{Ca}^{2+}$ depletion from the medium by EGTA influences a number of $\mathrm{Ca}^{2+}$-sensitive membrane proteins. One major $\mathrm{Ca}^{2+}$-dependent transmembrane protein found in the sarcolemma of myoblasts is integrin. Previous work from our group showed a change in the distribution of $\alpha 5$-integrin adhesion sites in C2C12 cells after EGTA treatment (12). Using indirect immunofluorescence, $\alpha 5$-integrin was detected in fibrillar adhesions at the terminations of stress fibers in both control and 24-h EGTA-treated C2C12 cells. Besides, a dense $\alpha 5$-integrin labeling was seen inside most treated cells, indicating a possible internalization of integrin after EGTA exposure (12). The effects of calcium depletion on desmin distribution observed in the present study may have been initiated by various cell surface components that require extracellular $\mathrm{Ca}^{2+}$, such as $\alpha 5$-integrin, which in turn can influence intracellular signaling pathways. It has been shown that desmin is present in the subsarcolemmal region in association with membrane and membraneassociated proteins, such as integrins (3).

In the present work, we found desmin aggregates in the cytoplasm of EGTA-treated C2C12 cells. Similar desmin dots and aggregates have been described as the major structural alteration in several desminopathies (10).
Desmin-related myopathies are characterized by the accumulation of desmin in certain inclusions, sarcoplasmic bodies, cytoplasmic bodies, and granulofilamentous material (11). The mechanisms that control the formation and aggregation of desmin filaments in desminopathies are still unclear. A chaperone protein, $\alpha \mathrm{B}$-crystalline, is involved in the correct assembly of desmin filaments and an impaired chaperone function could promote the increase in desmin aggregation (11).

The relation between changes in extracellular $\mathrm{Ca}^{2+}$ concentration and the expression and distribution of cytoskeletal proteins (such as desmin) could be directly mediated by changes in $\mathrm{Ca}^{2+}$-binding membrane molecules (such as integrins). Another possibility is that changes in extracellular $\mathrm{Ca}^{2+}$ concentration could indirectly change the intracellular $\mathrm{Ca}^{2+}$ concentration, which in turn could have an effect on the cytoskeletal components. One consequence of changes in intracellular $\mathrm{Ca}^{2+}$ concentration is the activation of $\mathrm{Ca}^{2+}$-activated enzymes, such as calpains, which are major proteolytic systems in skeletal muscle (16). Calpains are proteases that can selectively cleave cytoskeletal proteins, and desmin has been shown to be one of their major and first substrates both in vivo and in vitro; and calpains are found in association with the sarcolemma (17). We speculate that in the present study $\mathrm{Ca}^{2+}$ depletion might have induced a calpain-dependent cytoskeletal remodeling including desmin cleavage, resulting in the presence of desmin dots and aggregates in the cytoplasm.

The results presented in this paper suggest the requirement of extracellular $\mathrm{Ca}^{2+}$ for the regulation of cell shape and for the expression and distribution of desmin in skeletal muscle cells grown in culture. 


\section{References}

1. Herrmann H \& Aebi $U$ (2000). Intermediate filaments and their associates: multi-talented structural elements specifying cytoarchitecture and cytodynamics. Current Opinion in Cell Biology, 12: 7990.

2. Hijikata T, Murakami T, Ishikawa H \& Yorifuji H (2003). Plectin tethers desmin intermediate filaments onto subsarcolemmal dense plaques containing dystrophin and vinculin. Histochemistry and Cell Biology, 119: 109-123.

3. Ervasti JM (2003). Costameres: the Achilles' heel of Herculean muscle. Journal of Biological Chemistry, 278: 13591-13594.

4. Cary RB \& Klymkowsky MW (1994). Differential organization of desmin and vimentin in muscle is due to differences in their head domains. Journal of Cell Biology, 126: 445-456.

5. Wiche GJ (1998). Role of plectin in cytoskeleton organization and dynamics. Journal of Cell Science, 111: 2477-2486.

6. Mould AP, Garratt AN, Puzon-McLaughlin W, Takada Y \& Humphries $M$ (1998). Regulation of integrin function: evidence that bivalentcation-induced conformational changes lead to the unmasking of ligand-binding sites within integrin $\alpha 5 ß 1$. Biochemical Journal, 331 : 821-828.

7. Stuiver I, Ruggeri Z \& Smith JW (1996). Divalent cations regulate the organization of integrins alpha $V$ beta 3 and alpha $V$ beta 5 on the cell surface. Journal of Cell Physiology, 168: 521-531.

8. Maurer P, Hohenester E \& Engel J (1996). Extracellular calciumbinding proteins. Current Opinion in Cell Biology, 8: 609-617.

9. Capetanaki Y, Milner DJ \& Weitzer G (1997). Desmin in muscle formation and maintenance: knockouts and consequences. Cell
Structure and Function, 22: 103-116.

10. Goebel HH \& Warlo I (2000). Gene-related protein surplus myopathies. Molecular Genetics and Metabolism, 71: 267-275.

11. Carlsson L \& Thornell LE (2001). Desmin-related myopathies in mice and man. Acta Physiologica Scandinavica, 171: 341-348.

12. Mermelstein CS, Rebello MIL, Amaral LM \& Costa ML (2003). Changes in cell shape, cytoskeletal proteins and adhesion sites of cultured cells after extracellular $\mathrm{Ca}^{2+}$ chelation. Brazilian Journal of Medical and Biological Research, 36: 1111-1116.

13. Cho WJ, Kim EJ, Lee SJ, Kim HD, Shin HJ \& Lim WK (2000). Involvement of SPARC in in vitro differentiation of skeletal myoblasts. Biochemical and Biophysical Research Communications, 271: 630-634.

14. Mermelstein CS, Guma FCR, Mello TG, Fortuna VA, Guaragna RM, Costa M \& Borojevic R (2001). Induction of the lipocyte phenotype in murine hepatic stellate cells: reorganisation of the actin cytoskeleton. Cell and Tissue Research, 306: 75-83.

15. Mermelstein CS, Costa ML, Chagas C \& Moura Neto V (1996). Intermediate filaments in TPA-treated skeletal muscle cells in culture. Journal of Muscle Research and Cell Motility, 17: 199-206.

16. Goll DE, Thompson VF, Li H, Wei W \& Cong J (2003). The calpain system. Physiological Reviews, 83: 731-801.

17. Purintrapiban J, Wang MC \& Forsberg NE (2003). Degradation of sarcomeric and cytoskeletal proteins in cultured skeletal muscle cells. Comparative Biochemistry and Physiology. Part B, Biochemistry and Molecular Biology, 136: 393-401. 